\title{
A School-Based Intervention to Increase Lyme Disease Preventive Measures Among Elementary School-Aged Children
}

\author{
Nancy A. Shadick, Melanie J. Zibit, Elizabeth Nardone,, Alfred DeMaria, Jr., \\ Christine K. lannaccone, and Jing Cui ${ }^{1}$
}

\begin{abstract}
Purpose: Educational interventions to reduce Lyme disease (LD) among at-risk school children have had little study. The purpose of this study was to evaluate whether a short in-class LD education program based on social learning theory and the Health Belief Model (HBM) impacted a child's knowledge, attitude, and preventive behavior.

Methods: Students in grades 2-5 in 19 elementary schools were selected in an area that was highly endemic for LD. The children received an educational intervention or were on a wait list as controls. Their knowledge, attitudes, and self-reported preventive behaviors were surveyed before implementing the program and 1 year later. General linear regression analyses adjusting for age, gender, and baseline variables were used to measure the impact of the intervention.

Results: There were 3570 participants in the study: 1562 received the intervention, and 2008 were controls. The mean age for both groups was 9.1 years, with $53 \%$ women in the intervention group and 50\% women in the control group. The children in the intervention group increased their overall knowledge of LD more than the children in the control group (overall knowledge score improvement, mean difference (SD) $1.38(1.3)$ vs. $0.36(1.3) p<0.0001)$. All children in classes receiving the intervention reported an increase in precautionary behavior, positive attitude toward taking precautions, and self-efficacy compared with the wait list controls. Two LD cases were confirmed during the follow-up period, one in the intervention group and one in the controls.

Conclusions: These findings demonstrate that a short in-class educational program that includes elements of the HBM, including: (1) awareness and knowledge about the disease, (2) benefits of preventive behavior, and (3) confidence in ability to perform preventive behaviors can improve knowledge, attitude, and self-reported precautionary behavior among at-risk children. www.clinicaltrials.gov: NCT00594997
\end{abstract}

Key Words: Ixodes—Lyme disease.

\section{Introduction}

$\mathbf{L}$ YME DISEASE (LD), the most common vector-borne illness in the United States, continues to grow as a public health problem (Poland 2001, Bacon et al. 2008). Since the United States Centers for Disease Control and Prevention (CDC) began tracking LD in 1981, the number of reported cases in the United States has increased to nearly 35,000 per year (Bacon et al. 2008). Massachusetts, with 3830 confirmed cases in 2014, ranks second in the number of reported cases by state in the United States. Although these incidence numbers are large, it has been estimated that the actual number of cases occurring may be more than 10 times the reported cases (Hinckley et al. 2014).

Although LD affects all age groups, children from 5 to 9 years of age have one of the highest incidence rates (Orloski et al. 2000, Poland 2001, Bacon et al. 2008). Tick bite prevention remains a challenge in this age group, but it is an

\footnotetext{
${ }^{1}$ Division of Rheumatology, Immunology \& Allergy, Brigham \& Women's Hospital, Harvard Medical School, Boston, Massachusetts.

${ }^{2}$ Advocates, Inc., Framingham, Massachusetts.

${ }^{3}$ Bureau of Infectious Disease and Laboratory Sciences, Massachusetts Department of Public Health, Jamaica Plain, Massachusetts.

(C) Nancy A. Shadick, et al., 2016; Published by Mary Ann Liebert, Inc. This Open Access article is distributed under the terms of the Creative Commons Attribution Noncommercial License (http://creativecommons.org/licenses/by-nc/4.0/) which permits any noncommercial use, distribution, and reproduction in any medium, provided the original author(s) and the source are credited.
} 
important public health goal. Falco found that children less than 10 years old have a high risk of $L D$, because they receive more bites from the nymphal ticks that are harder to find on the body, and less likely to have ticks removed in time to prevent transmission (Falco et al. 1996). Furthermore, one study in the Netherlands demonstrated that among school children, moral norms, emotional attitude, anticipated regret, role models, and self-efficacy were positively associated with tick inspection behavior (de Vries and van Dillen 2002), indicating that simply educating children about the signs and symptoms of LD may not enhance tick bite prevention behavior.

We performed a school-based intervention based on elements of social learning theory and the Health Belief Model (HBM) in schools in a coastal area of Essex County on the North Shore of Massachusetts. Essex County, with a population of 743,167 , is highly endemic for LD. The purpose of the study was to evaluate whether this short, in-class education program can increase the practice of precautionary behavior by enhancing the sense of risk, using modeling techniques and improving self-efficacy in elementary schoolaged children.

\section{Materials and Methods}

\section{School recruitment and study design}

A randomized, controlled, pretest post-test design study was performed in nine school districts in Essex County, on the North Shore of Massachusetts (Fig. 1). The unit of randomization was the school district, and consent was obtained from the 19 elementary school principals and the parents of children in each school. Schools were selected based on community location (coastal region of Massachusetts) and a high rate of LD. Recruitment totaled $\sim 2000$ students per group. The sampling procedure included inviting nine school districts to participate, and then randomly assigning one school district to the intervention or control.

Schools were initially contacted by phone through the superintendents and followed up with presentations to elementary school principals, teachers, school nurses, and/or school boards. All schools $(n=19)$ agreed to participate. Before our research, the parents of each child received a letter in the mail briefly describing the study. All consent and other materials were reviewed and approved by the Institutional Review Board at the Brigham and Women's Hospital.

\section{Description of theory-based intervention}

The HBM (Becker et al. 1974, Rosenstock 1974, Rosenstock et al. 1988), an explanatory model often cited as a descriptor of health behavior, formed the theoretical basis for the intervention (Rimer et al. 2001, Bandura 2004). The HBM predicts how likely an individual is to practice certain health behaviors using four components of perception: perceived susceptibility, perceived severity, perceived barriers, and perceived benefits, accounting for self-efficacy and socio-demographic variables. The questionnaires assessing students evaluated their beliefs across these four dimensions, as well as their perceived selfefficacy, both before and after the intervention.

The intervention intended to teach children that they are susceptible to LD, that the disease can be serious, that ticks can carry the pathogen, that they have the ability to perform preventive tick-checking behaviors, that the behaviors designed to prevent LD do not need to be time-consuming or difficult, and that performing the preventive behaviors will decrease the likelihood of getting sick (Becker et al. 1974, Rosenstock 1974, Rosenstock et al. 1988). The elements of the HBM and how it was presented to the children are outlined in Figure 2.

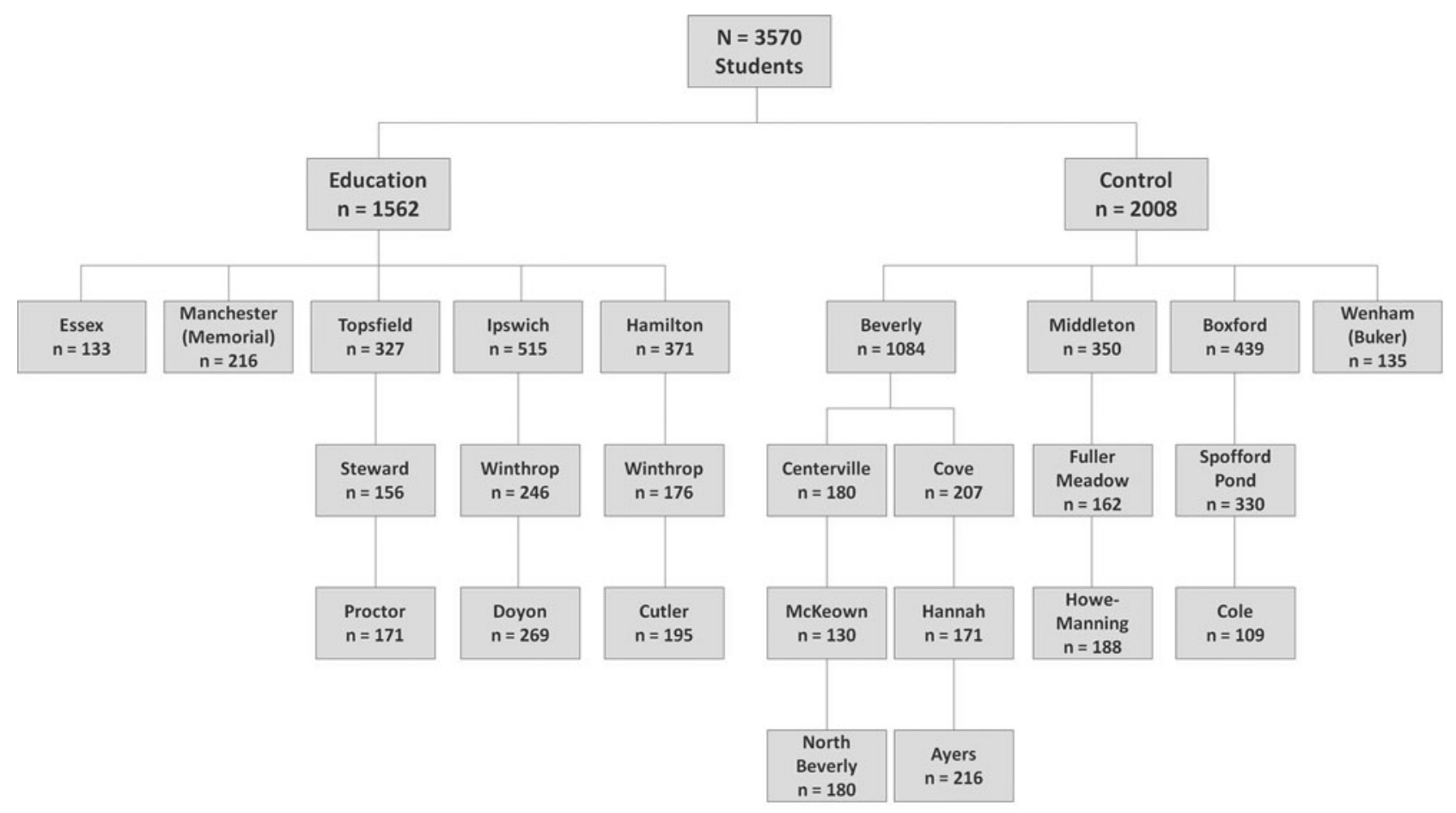

FIG. 1. Participants in elementary schools enrolled in the Lyme disease (LD) education program. 


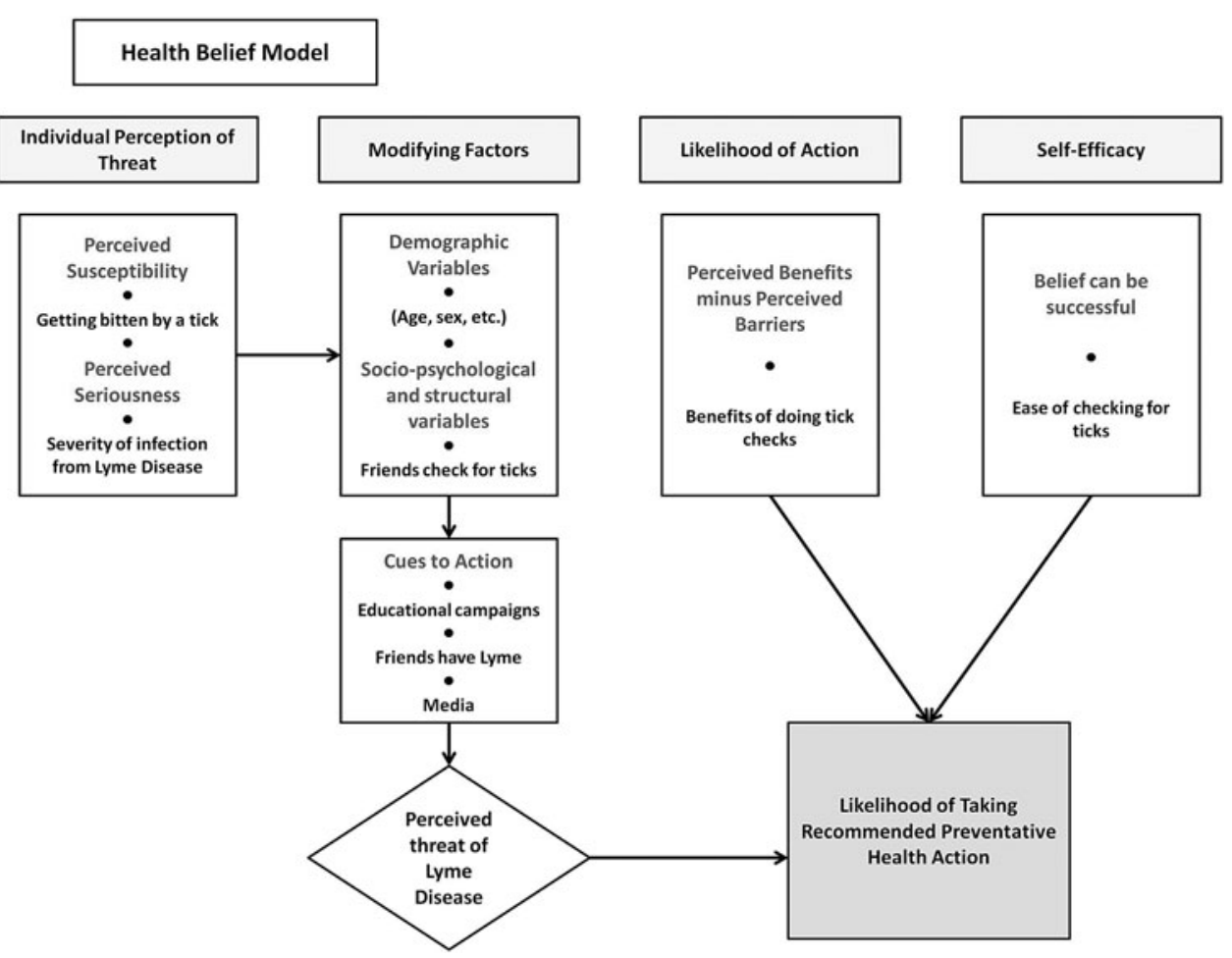

Additionally, the intervention used learner-centered teaching strategies that have been shown to improve the learning process for children and to build better personal competence. In learner-centered teaching, "teachers do less telling; students do more discovering" (Cheang 2009, Weimer 2013). Instructors model behavior and then encourage children to learn through discovery, feedback, and interaction with each other.

The curriculum devised, using the "Feel, Find, Free" slogan, consisted of a PowerPoint presentation teaching about the tick lifecycle, how ticks and humans interact, where ticks are found in nature, what steps to take to prevent tick bites, and a series of follow-up activities that encourage interaction between students and teachers to reinforce the knowledge gained. Students in grade two watched and discussed a video, compared ticks with other bugs, and searched for hidden ticks in a coloring book. Students in grades three through five played word-finding games with LD and tick lifecycle terms and discussed effective preventive measures in groups. A life-sized mannequin arm with deceased deer ticks from different stages in the life cycle was passed around so that children could see and feel ticks. Children received a supplemental packet to take home to their parents with an informational brochure, a tick check shower card, a tick dock card (card for documenting removal of an attached tick and for preserving the tick), and a tick feel card. Throughout the presentation and activities, students were repeatedly asked questions to reinforce what they were taught. For more details, please see the website www .BWHPreventLyme.org.

Several weeks after the presentation, students viewed a 45 min vaudeville-type performance, modified from a previous LD prevention program given by professional health educators to reinforce educational messages about LD prevention (Daltroy et al. 2007). The performers, "Dr. Bull's Eye" and his assistant "Rusty Tweezers," employed song, juggling, and dance to engage children in a fun way about LD prevention.

\section{Procedures}

Questionnaires asking about prior knowledge of LD, attitudes toward prevention, and self-reported preventive behaviors were distributed to the intervention and control groups before implementing the program. During the late fall/winter (October or November) of each year from 2004 to 2006, researchers from Brigham and Women's Hospital distributed the baseline survey to children in the classroom in grades 2-5.

The classroom intervention was delivered in the early spring (March or April) by research personnel while the teachers were in the classroom and in the late fall administered the same survey as a post-test. The control students received the educational presentation after the follow-up survey was completed.

\section{Analysis plan}

Three outcome measures, knowledge of LD transmission, self-reported tick bite precautionary behaviors, and attitudes toward taking precautions, were measured (Tables 2, 3, and 5). A LD knowledge score was created from totaling the number of correct answers on the six knowledge questions (Table 4). Precautionary behavior outcomes were graded on a linear scale quantifying the amount of practice (see Table 2 as an example). A score with a higher value indicated an increase in the desired behavior.

Children were asked whether they ever had LD, how many of their friends may have had LD, how many tick bites they believed that they had got in the past summer, and how often they wore long pants to keep ticks off. The children were also asked at their follow-up survey whether they had had LD in the past year since their last questionnaire. If they answered 


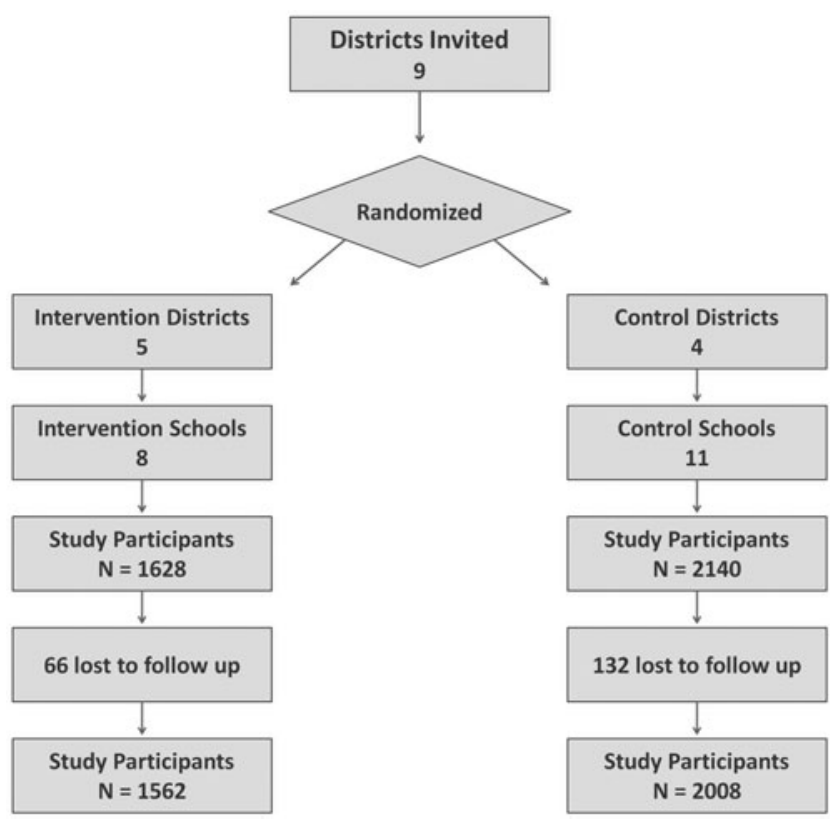

FIG. 3. Flow chart of the LD education program.

yes, we mailed a letter to their parents asking to confirm that they had a new case of LD and if so, we then requested permission to review their medical records.

Descriptive statistics were tabulated and compared to determine the demographic and outcome measure balance between intervention and controls. $\mathrm{T}$ tests or chi-squared analyses were performed as required. Questions with linear or Likert scales were graded with higher scores indicating a better outcome. Linear regression modeling (PROC GLM) was used to compare linear outcomes that were measured as a change of each outcome (an increase, no change, decrease, or reduction in the behavior), adjusting for age, sex, and pretest variable value to account for the differences in student age, gender, and baseline variable value. Outcomes of the intervention and control groups were presented adjusted for covariates. Effectsize estimates were calculated as standardized mean difference controlling for covariates. We also performed an intent-to-treat analysis to evaluate whether values carried forward for dropouts changed the outcomes. All analyses were done using SAS v. 9.4 (SAS Institute, Cary, NC).

\section{Results}

\section{Baseline characteristics}

Figure 3 details the recruitment of subjects; 3768 enrolled in the program, and 1562 intervention students and 2008 control students completed the protocol (5\% dropped out) (Table 1). There were five intervention and four control school districts. The cohort had an average age of 9.1 years (standard deviation \pm 1.2 ) $51.1 \%$ female overall. There was a relatively even overall distribution of participants across grades $(23.1 \%$ in second grade, $25.9 \%$ in third grade, $25.1 \%$ in fourth grade, and $25.9 \%$ in fifth grade). The intervention group had slightly more students in higher grades $(p=0.05)$. All baseline behaviors and knowledge measures were slightly higher in the intervention group versus the waitlist controls (Tables 2, 3, and 5).

\section{Practice of precautionary behaviors pre- and postintervention in intervention and control students}

In questions based on the four precautionary practices taught to prevent tick bites, the intervention group showed significant improvement postintervention over the controls in all questions (Table 2). After the intervention, more students ( $15 \%$ increase) in the intervention group said they checked behind their knees, compared with students (5.4\% increase) in the control group $(p<0.0001)$. There also was an increase in the frequency of the children's "checking behind the ears" in the intervention group compared with the control group $(p<0.0001)$. Both groups saw a decrease in the number of students responding that they "always" wear long pants to keep the ticks off and an increase in the number of students responding that they "never" wear long pants to keep the ticks off, but the control students reported these behaviors significantly more frequently $(p=0.002)$.

For the question "how often do you check yourself for ticks?" the wait list control group reported a decrease postintervention in the number of students reporting that they "always" check themselves for ticks; both groups reported an increase in the number of students reporting that they " usually" check themselves for ticks. There was a small but significant improvement in the reported frequency of tick checking in the intervention group versus the control group on this question (beta $=0.06, p<0.02$ ).

\section{Postintervention change in LD knowledge in intervention and control students}

A summed knowledge score for each student was created by totaling the number correct out of the six knowledge questions listed in Table 3. The intervention students improved their overall knowledge score more than the control students (mean improvement, 1.38 (SD1.31) vs. 0.35 (SD 1.30), $p<0.0001$ ) at the end of the program. As the intervention students had a higher overall knowledge score

TABle 1. Socio-Demographic Information for InTERVEntion and CONTRol Students

\begin{tabular}{lccr}
\hline Variable & Total population $(\mathrm{n}=3570)$ & Intervention $(\mathrm{n}=1562)$ & Control $(\mathrm{n}=2008)$ \\
\hline Age, M (SD) & $9.1( \pm 1.2)$ & $9.1( \pm 1.2)$ & $9.1( \pm 1.2)$ \\
Sex $(n, \%$ female) & $1825(51.1)$ & $822(52.6)$ & $1003(50.1)$ \\
Grade, $n$ (\% total) & & & \\
$\quad$ Second & $824(23.1)$ & $335(21.4)$ & $489(24.4)$ \\
Third & $924(25.9)$ & $410(26.3)$ & $514(25.7)$ \\
Fourth & $896(25.1)$ & $422(27.1)$ & $474(23.6)$ \\
Fifth & $921(25.9)$ & $393(25.2)$ & $528(26.3)$ \\
\hline
\end{tabular}


Table 2. Practice of Precautionary Behaviors Pre- and Postintervention IN INTERVENTION AND CONTROL STUDENTS

\begin{tabular}{|c|c|c|c|c|c|c|c|}
\hline & \multicolumn{2}{|c|}{ Intervention $(\mathrm{n}=1562)$} & \multicolumn{2}{|c|}{ Control $(\mathrm{n}=2008)$} & \multirow[b]{2}{*}{$\beta$} & \multirow{2}{*}{$\begin{array}{l}\text { Effect } \\
\text { Size }\end{array}$} & \multirow[b]{2}{*}{$\mathrm{p}-$ Value } \\
\hline & Pre & Post & Pre & Post & & & \\
\hline \multicolumn{8}{|c|}{ How often do you check yourself for ticks? $n(\%)$} \\
\hline Always & $187(12.0)$ & $185(12.0)$ & $272(13.6)$ & $232(11.6)$ & 0.06 & 0.068 & 0.02 \\
\hline Usually & $402(25.8)$ & $422(27.2)$ & 412 (20.6) & $477(23.8)$ & & & \\
\hline Sometimes & $883(56.8)$ & $861(55.6)$ & $1107(55.2)$ & $1083(54.2)$ & & & \\
\hline Never & $81(5.2)$ & $82(5.2)$ & $211(10.6)$ & $205(10.2)$ & & & \\
\hline \multicolumn{8}{|c|}{ When you check yourself for ticks, do you usually, $n(\%)$} \\
\hline check behind your ears & $1313(84.4)$ & $1372(88.6)$ & $1484(74.2)$ & $1582(79.4)$ & 0.06 & 0.13 & $<0.0001$ \\
\hline check behind your knees & $1075(69.0)$ & $1302(84.0)$ & $1302(65.2)$ & 1409 (70.6) & 0.12 & 0.22 & $<0.0001$ \\
\hline check your hands & $768(49.4)$ & $721(46.6)$ & 1009 (50.4) & 1047 (52.6) & -0.06 & -0.09 & $<0.0001$ \\
\hline \multicolumn{8}{|c|}{ How many days a week do you play in woods? $n(\%)$} \\
\hline Almost every day & $188(12.2)$ & $179(11.6)$ & $229(11.4)$ & $196(9.8)$ & -0.07 & -0.08 & 0.01 \\
\hline $3-4$ days a week & $195(12.6)$ & $185(12.0)$ & $200(10.0)$ & $193(9.8)$ & & & \\
\hline $1-2$ days a week & $690(44.6)$ & $672(43.4)$ & $793(39.8)$ & $800(40.2)$ & & & \\
\hline Never & $476(30.8)$ & $514(33.2)$ & $774(38.8)$ & $798(40.2)$ & & & \\
\hline \multicolumn{8}{|c|}{ How often do you wear long pants just to keep the ticks off you? $n(\%)$} \\
\hline Always & 290 & 257 (16.6) & $444(22.2)$ & $318(16.0)$ & 0.09 & 0.08 & 0.002 \\
\hline Usually & $507(32.6)$ & $526(34.0)$ & $619(31.0)$ & $615(30.8)$ & & & \\
\hline Sometimes & $611(39.2)$ & $593(38.4)$ & $703(35.2)$ & $781(39.2)$ & & & \\
\hline Never & $148(9.6)$ & $172(11.2)$ & 232 (11.6) & $277(14.0)$ & & & \\
\hline
\end{tabular}

Missing data for each question range from 5 to 21.

${ }^{a}$ Comparing change from preintervention with postintervention between intervention and control students, adjusted for age, sex, and preintervention variable.

Table 3. Knowledge of Lyme Disease Pre- and Postintervention in Intervention and Control Students

\begin{tabular}{|c|c|c|c|c|c|c|}
\hline & \multicolumn{2}{|c|}{ Intervention $(\mathrm{n}=1562)$} & \multicolumn{2}{|c|}{ Control $(\mathrm{n}=2008)$} & \multirow{2}{*}{$\begin{array}{l}\text { Effect } \\
\text { size }\end{array}$} & \multirow[b]{2}{*}{$\mathrm{p}$-Value } \\
\hline & Pre & Post & Pre & Post & & \\
\hline \multicolumn{7}{|c|}{ A tick can get on you when, $n(\%)$} \\
\hline You brush against it & $444(28.5)$ & $1202(77.2)$ & $417(20.8)$ & $492(24.6)$ & \multirow[t]{3}{*}{0.9} & \multirow[t]{3}{*}{$<0.0001$} \\
\hline It flies into you & $62(4.0)$ & $13(0.8)$ & $134(6.7)$ & $75(3.7)$ & & \\
\hline It jumps onto you & $1052(67.5)$ & $343(22.0)$ & $1455(72.6)$ & $1429(71.4)$ & & \\
\hline \multicolumn{7}{|c|}{ Can you get sick from a tick bite? $n(\%)$} \\
\hline Yes & 1435 (91.9) & $1495(96.0)$ & 1674 (83.6) & $1795(89.8)$ & \multirow[t]{3}{*}{0.13} & \multirow[t]{3}{*}{0.28} \\
\hline No & $41(2.6)$ & $27(1.7)$ & 99 (4.9) & $47(2.4)$ & & \\
\hline Not sure & $86(5.5)$ & $36(2.3)$ & $229(11.4)$ & $157(7.9)$ & & \\
\hline \multicolumn{7}{|c|}{ Do you feel it when a tick bites you? $n(\%)$} \\
\hline Yes & $246(15.8)$ & $117(7.5)$ & 415 (20.7) & $285(14.2)$ & \multirow{3}{*}{0.23} & \multirow{3}{*}{0.0029} \\
\hline No & $995(63.8)$ & $1222(78.4)$ & $1149(57.3)$ & $1279(63.9)$ & & \\
\hline Not sure & $318(20.4)$ & $219(14.1)$ & $440(22.0)$ & $437(21.8)$ & & \\
\hline \multicolumn{7}{|c|}{ What is one way to find a tick? $n(\%)$} \\
\hline Smell it & $5(0.3)$ & $8(0.5)$ & $13(0.6)$ & $9(0.4)$ & \multirow[t]{4}{*}{0.12} & \multirow[t]{4}{*}{0.13} \\
\hline Feel for it & $1444(92.6)$ & $1526(97.8)$ & $1682(83.8)$ & $1857(92.8)$ & & \\
\hline Hear it & $15(1.0)$ & $3(0.2)$ & $57(2.8)$ & $20(1.0)$ & & \\
\hline Cannot find it & $95(6.1)$ & $24(1.5)$ & $255(12.7)$ & $116(5.8)$ & & \\
\hline \multicolumn{7}{|c|}{ How long does a tick need to be on you before you get Lyme disease? $n(\%)$} \\
\hline $1 \mathrm{~h}$ & $188(12.1)$ & $68(4.4)$ & $342(17.1)$ & $264(13.3)$ & \multirow[t]{3}{*}{0.59} & \multirow[t]{3}{*}{$<0.0001$} \\
\hline 1 day & $684(44.2)$ & $1294(83.8)$ & $819(41.0)$ & $893(45.0)$ & & \\
\hline 4 days & $677(43.7)$ & $182(11.8)$ & $835(41.8)$ & $828(41.7)$ & & \\
\hline \multicolumn{7}{|c|}{ What time of year can you get Lyme disease? $n(\%)$} \\
\hline Spring & $578(37.0)$ & $959(61.6)$ & $627(31.2)$ & $811(40.4)$ & \multirow[t]{6}{*}{0.35} & \multirow[t]{6}{*}{$<0.0001$} \\
\hline Summer & $1087(69.6)$ & 1179 (75.7) & 1457 (72.6) & 1434 (71.4) & & \\
\hline Fall & $614(39.3)$ & $1041(66.8)$ & $665(33.1)$ & $872(43.4)$ & & \\
\hline Winter & $418(26.8)$ & $833(53.5)$ & $504(25.1)$ & $663(33.0)$ & & \\
\hline Anytime & $410(26.2)$ & $825(53.0)$ & $497(24.8)$ & $653(32.5)$ & & \\
\hline I do not know & $178(11.4)$ & $112(7.2)$ & $262(13.0)$ & 248 (12.4) & & \\
\hline
\end{tabular}

Correct answer in italics.

${ }^{a}$ Comparing change from preintervention with postintervention between intervention and control students, adjusted for age, sex, and preintervention variable. 
Table 4. Composite Knowledge Score FOR INTERVENTION AND CONTROL STUDENTS POSTINTERVENTION

\begin{tabular}{lccc}
\hline & $\begin{array}{c}\text { Intervention } \\
\text { students } \\
(\mathrm{n}=1562)\end{array}$ & $\begin{array}{c}\text { Control } \\
\text { students } \\
(\mathrm{n}=2008)\end{array}$ & $\mathrm{p}$-Value \\
\hline $\begin{array}{c}\text { Preintervention } \\
\text { mean knowledge }\end{array}$ & $3.47(1.12)$ & $3.11(1.18)$ & $<0.0001$ \\
$\begin{array}{c}\text { score, M (SD) } \\
\text { Postintervention } \\
\text { mean knowledge } \\
\text { score, M (SD) }\end{array}$ & $4.85(1.09)$ & $3.47(1.18)$ & $<0.0001$ \\
$\begin{array}{c}\text { Difference, M (SD) } \\
\text { a }\end{array}$ & $1.38(1.31)$ & $0.36(1.30)$ & $<0.0001$ \\
\hline
\end{tabular}

Number of correct answers to the six knowledge questions listed in Table 3; effect size is 0.73 .

${ }^{a}$ Comparing change from preintervention with postintervention between intervention and control students, adjusted for age, sex, and preknowledge score.

than controls before the program started, the mean differences between groups were adjusted for age, sex, and baseline score to account for these differences (Table 4).

\section{Changes in perception of self-efficacy pre- and postintervention for intervention and control students}

There were significant differences between the two groups in response to the self-efficacy questions (Table 5). More in- tervention students responded that they could find a tick on themselves after the intervention $(3.6 \%$ change for intervention students, $2.4 \%$ change for control students, $p<0.0001$ ) and reported doing their own tick checks after the intervention (5.8\% change in the intervention group, $4.0 \%$ change in the control group, $p=0.001)$. More students in the intervention group also reported that it was "very easy" to find a tick when coming in from outside compared with the controls $(4.8 \%$ change in the intervention group, $2.2 \%$ change in the control group, $p<0.0001)$.

\section{LD cases}

Thirty eight children in the intervention group compared with 34 children in the control group reported a new case of LD at follow-up. This represented 73 of 3570 (2\%) children reporting a new case of LD. Forty four of the parents of the 73 children returned the questionnaire. Among five parents who reported $\mathrm{LD}$, only two (one in the intervention group and one in the control group) were confirmed by their pediatrician's record. One case was a treated tick bite, and two were LD cases that occurred before the study enrollment. This rate $(56 / 100,000)$ is similar to the overall incidence rate of LD physician reports to the Massachusetts Department of Public Health for 5-9 year-old children of $61.5 / 100,000$ in 2005.

\section{Discussion}

Tick bite control precautions are recommended to reduce the transmission of LD (Cartter et al. 1989, Poland 2001, de

Table 5. Changes in Perception of Self-Efficacy Pre- and Postintervention FOR INTERVENTION AND CONTROL STUDENTS

\begin{tabular}{|c|c|c|c|c|c|c|c|}
\hline & \multicolumn{2}{|c|}{ Intervention $(\mathrm{n}=1562)$} & \multicolumn{2}{|c|}{ Control $(\mathrm{n}=2008)$} & \multirow[b]{2}{*}{$\beta$} & \multirow{2}{*}{$\begin{array}{c}\text { Effect } \\
\text { Size }\end{array}$} & \multirow[b]{2}{*}{$\mathrm{p}$-Value } \\
\hline & Pre & Post & Pre & Post & & & \\
\hline \multicolumn{8}{|c|}{ Do you think you can find a tick on yourself? $n(\%)$} \\
\hline Yes & $1200(77.0)$ & $1245(80.6)$ & $1343(67.2)$ & $1390(69.6)$ & \multirow[t]{3}{*}{0.07} & \multirow[t]{3}{*}{0.15} & \multirow[t]{3}{*}{$<0.0001$} \\
\hline No & $202(13.0)$ & $155(10.0)$ & 407 (20.4) & $339(17.0)$ & & & \\
\hline Not sure & $156(10.0)$ & $146(9.4)$ & $251(12.6)$ & $271(13.6)$ & & & \\
\hline \multicolumn{8}{|c|}{ How sure are you that you will get a tick bite this summer? $n(\%)$} \\
\hline Very sure & $170(11.0)$ & $132(8.6)$ & $184(9.2)$ & $137(6.8)$ & \multirow[t]{4}{*}{-0.11} & \multirow[t]{4}{*}{-0.11} & \multirow[t]{4}{*}{0.0002} \\
\hline Pretty sure & $400(25.8)$ & $317(20.4)$ & $369(18.4)$ & $286(14.4)$ & & & \\
\hline Slightly sure & $463(29.8)$ & $494(31.8)$ & $580(29)$ & $585(29.4)$ & & & \\
\hline Not so sure & $523(33.6)$ & $608(39.2)$ & $864(43.2)$ & $983(49.4)$ & & & \\
\hline \multicolumn{8}{|c|}{ When you come in from playing outdoors, is it easy or hard to check yourself for ticks? $n(\%)$} \\
\hline Very easy & $133(8.6)$ & $209(13.4)$ & $222(11.0)$ & $261(13.2)$ & \multirow[t]{5}{*}{0.16} & \multirow[t]{5}{*}{0.11} & \multirow[t]{5}{*}{$<0.0001$} \\
\hline Easy & $699(45.0)$ & $784(50.6)$ & 733 (36.6) & $834(42.0)$ & & & \\
\hline Hard & 430 (27.6) & $315(20.2)$ & $525(26.2)$ & $425(21.4)$ & & & \\
\hline Very hard & $46(3.0)$ & $30(2.0)$ & $87(4.4)$ & $69(3.4)$ & & & \\
\hline I do not check & $247(15.8)$ & $214(13.8)$ & $435(21.8)$ & $396(20.0)$ & & & \\
\hline \multicolumn{8}{|c|}{ Who helps you check for ticks most of the time? $n(\%)^{\mathrm{b}}$} \\
\hline Do not check & $43(2.8)$ & $84(5.4)$ & $134(6.6)$ & $165(8.2)$ & \multirow[t]{4}{*}{0.05} & \multirow[t]{4}{*}{0.09} & \multirow[t]{4}{*}{0.001} \\
\hline Check myself & $137(8.8)$ & $227(14.6)$ & $125(6.2)$ & $206(10.2)$ & & & \\
\hline Grownup at school & $71(4.6)$ & $30(2.0)$ & $71(3.6)$ & $39(2.0)$ & & & \\
\hline Grownup at home & $1311(84)$ & $1211(77.8)$ & $1690(84.2)$ & 1599 (79.6) & & & \\
\hline
\end{tabular}

Missing data for each question range from 0 to 23 .

${ }^{a}$ Comparing change from preintervention with postintervention between intervention and control students, adjusted for age, sex, and preintervention variable.

bWe ranked "check myself" as the highest score, "grownup at school" and "grownup at home" as the same score, and "do not check" as the lowest score. 
Vries and van Dillen 2002, Daltroy et al. 2007 American Academy of Pediatrics 2000, Hayes and Piesman 2003, Clark and $\mathrm{Hu}$ 2008, Gould et al. 2008, Connally et al. 2009, Eisen and Mead 2014). Recent LD studies in adults indicate that understanding a population's risk factors, attitudes toward disease prevention, and past experience with LD are important in devising a successful prevention strategy, particularly enhancing self-efficacy for taking precautions (Cartter et al. 1989, Centers for Disease Control 1992, Ley et al. 1995, Shadick et al. 1997, Armstrong et al. 2001, Smith et al. 2001, Malouin et al. 2003, Herrington 2004, McKenna et al. 2004, Daltroy et al. 2007, Gould et al. 2008, Vazquez et al. 2008). School-aged children, in particular, are at great risk for contracting LD, because they frequently play outdoors-in their backyards, playgrounds, on school grounds. Research has demonstrated that infections likely occur in residential areas during routine activities (Poland 2001).

The prevention of pediatric LD is an important initiative, and school health programs are one of the most efficient modalities to enhance public health (Redican et al. 1979). This is one of the first studies to evaluate an inclass LD educational program using social learning theory and the HBM. In this study, we demonstrated that compared with control school children, the educational program produced modest improvements in the intervention school children's knowledge, perceived susceptibility, selfefficacy, and self-reported practice of precautionary behavior. The effect we demonstrated was durable months after the intervention.

Our educational intervention used pedagogical theory of how students learn to impact changes in health behavior. This program incorporated question-and-answer sessions, hands-on activities, and engaging entertainment to reinforce learning and desired behavior, with the intention to provide children with usable actions. The design of the program gave students the opportunity to become active learners, to practice preventive behavior so that they are better prepared to transfer what they learned in the classroom into actions outside or at home (Payton et al. 2000).

The educational intervention also used a multi-faceted approach to embed elements of social learning theory and the HBM into the intervention (Rosenstock et al. 1988). The elements included observing tick-checking behavior (modeling), awareness of the consequences of having LD, and instilling the belief that each student is capable of carrying out preventive behaviors (self-efficacy). During the educational intervention, the health educator not only talked about tick-checking behavior but also demonstrated it and had children replicate it. The children were learning together with peers in their classroom, making it socially acceptable and reinforcing the tick-checking behavior. A similarly designed, active school educational program was successful in promoting sun protection behavior in children in grades 6-8 in Colorado, New Mexico, and Arizona (Buller et al. 2006).

Our study had several limitations. Because all school districts were located in endemic areas for LD and other tickborne illnesses, there was already a high level of awareness of LD. This would have limited the intervention's ability to produce a large effect. In addition, although we randomly selected intervention towns and controls, our intervention group had slightly higher baseline scores. We adjusted our analyses to compensate for this difference. Additionally, our study did not incorporate parental attitudes. In a study by de Vries and van Dillen (2002), predictors of parental tick inspection were parental norms, having a positive attitude, anticipated regret, having role models, and stressing self efficacy. In a preliminary analysis of this study's parental attitudes (Zibit 2008), correlates of a child's practice of precautionary behaviors were found to be parents' tick check monitoring, higher tick check self-efficacy, and a positive attitude toward precautionary behaviors. Future LD schoolbased prevention programs would benefit from incorporating parental attitudes into their programs.

Another limitation of our program is that we did not have a control arm implemented to assess the differential impact of the live performance compared with the in-class curricular materials. It may be that the live performance had a larger effect on the children's knowledge and attitude change than the in-class curriculum, and our study design could not answer this question. Future trials could include an additional study arm to evaluate the differential benefits of these two different educational methods.

A further limitation of our study was that behaviors were self-reported and could not be independently validated. Children who underwent our educational intervention may have been more likely to report an increase in their precautionary behavior as a result of the study. Additionally, a better indicator of the impact of the intervention would be more directly measured outcomes such as the number of ticks found on study participants and the outcomes of the tick encounters. Daily diaries of tick encounters or reports from parents about the frequency of tick bites might also be a better direct measure of the intervention's effect. A suggestion for future studies would be to include parental input about the frequency of the children's precautionary behavior.

In addition, although the handouts in the intervention were made to be grade specific, we used the same intervention with all grade levels. Our results suggested that the intervention may have worked better in grades 3-5. In discussion with some of the school personnel, we found that the juggler performance worked well for all children but the younger children (grade 2) needed a shorter in-class session, that is, $15 \mathrm{~min}$, which was more appropriate to their developmental level.

In addition, although there were many large statistical differences between our intervention and control groups due to the very large sample sizes, the clinical significance of these differences is more modest. We included the effect sizes for each change to help the reader determine the strength of these effects; only two out of six of the knowledge questions and none of the self-efficacy questions had improvements where the effect sizes were greater than 0.5 , which indicates only modest improvements in many of the outcomes. Furthermore, we were unable to evaluate whether these changes significantly impacted the incidence of LD, since only two cases were confirmed by the study children's pediatricians, a number too low to detect an effect of our intervention. Some of the children in the younger grades who reported having had LD had parents who reported that they actually had a tick bite and were given prophylactic antibiotics. Although the general knowledge score about LD improved, there was still some confusion about the difference between an infection and prophylaxis for a tick bite. 


\section{Conclusions}

In summary, LD affects school-aged children at a particularly high rate. Educational interventions to reduce LD among at-risk school children have had little study. This intervention demonstrated that a short in-class LD education program based on social learning theory and the HBM can impact a child's knowledge, attitude, and self-reported preventive behavior. The program was well received by the students and parents (there was a high rate of participation and follow-up); teachers and school administrators appreciated the help. The study suggests that this educational initiative may be successfully used in other at-risk communities. Future studies might focus on whether this intervention can reduce the rate of tick-borne illness, how long the intervention impacts self-reported tick bite prevention behavior, and to what extent parental attitudes impact a child's risk and their self-reported behaviors.

\section{Acknowledgments}

This study is funded by the CDC/NCID UO1 C1000164, Arthritis Foundation, and American Lyme Disease Foundation. The authors would like to thank the administration, teachers, nurses, and students for their participation in this research.

\section{Author Disclosure Statement}

No competing financial interests exist.

\section{References}

American Academy of Pediatrics. Committee on infecious diseases. Prevention of Lyme disease. Pediatrics 2000; 105(1 Pt 1):142-147.

Armstrong PM, Brunet LR, Spielman A, Telford SR, 3rd. Risk of Lyme disease: Perceptions of residents of a Lone Star tickinfested community. Bull World Health Organ 2001; 79:916925.

Bacon RM, Kugeler KJ, Mead PS; Centers for Disease Control and Prevention. Surveillance for Lyme disease-United States, 1992-2006. MMWR Surveill Summ 2008; 57:1-9.

Bandura A. Health promotion by social cognitive means. Health Educ Behav 2004; 31:143-164.

Becker MH, Drachman RH, Kirscht JP. A new approach to explaining sick-role behavior in low-income populations. Am J Public Health 1974; 64:205-216.

Buller DB, Taylor AM, Buller MK, Powers PJ, et al. Evaluation of the Sunny Days, Healthy Ways sun safety curriculum for children in kindergarten through fifth grade. Pediatr Dermatol 2006; 23:321-329.

Cartter ML, Farley TA, Ardito HA, Hadler JL. Lyme disease prevention-knowledge, beliefs, and behaviors among high school students in an endemic area. Conn Med 1989; 53:354 356.

Centers for Disease Control. Lyme disease knowledge, attitudes, and behaviors-Connecticut, 1992. MMWR Morb Mortal Wkly Rep 1992; 41:505-507.

Cheang KI. Effect of learner-centered teaching on motivation and learning strategies in a third-year pharmacotherapy course. Am J Pharm Educ 2009; 73:42.
Clark RP, Hu LT. Prevention of lyme disease and other tickborne infections. Infect Dis Clin North Am 2008; 22:381396, vii.

Connally NP, Durante AJ, Yousey-Hindes KM, Meek JI, et al. Peridomestic Lyme disease prevention: Results of a population-based case-control study. Am J Prev Med 2009; 37: 201-206.

Daltroy LH, Phillips C, Lew R, Wright E, et al. A controlled trial of a novel primary prevention program for Lyme disease and other tick-borne illnesses. Health Educ Behav 2007; 34:531-542.

de Vries H, van Dillen S. Prevention of Lyme disease in Dutch children: Analysis of determinants of tick inspection by parents. Prev Med 2002; 35:160-165.

Eisen R, Mead P. Prevention of Lyme disease. In: UpToDate, Steere, AC (Ed), UpToDate Waltham, MA (Accessed on January 6, 2016).

Falco RC, Fish D, Piesman J. Duration of tick bites in a Lyme disease-endemic area. Am J Epidemiol 1996; 143: 187-192.

Gould LH, Nelson RS, Griffith KS, Hayes EB, et al. Knowledge, attitudes, and behaviors regarding Lyme disease prevention among Connecticut residents, 1999-2004. Vector Borne Zoonotic Dis 2008; 8:769-776.

Hayes EB, Piesman J. How can we prevent Lyme disease? N Engl J Med 2003; 348:2424-2430.

Herrington JE. Risk perceptions regarding ticks and Lyme disease: A national survey. Am J Prev Med 2004; 26 : 135-140.

Hinckley AF, Connally NP, Meek JI, Johnson BJ, et al. Lyme disease testing by large commercial laboratories in the United States. Clin Infect Dis 2014; 59:676-681.

Ley C, Olshen EM, Reingold AL. Case-control study of risk factors for incident Lyme disease in California. Am J Epidemiol 1995; 142(9 Suppl): S39-S47.

Malouin R, Winch P, Leontsini E, Glass G, et al. Longitudinal evaluation of an educational intervention for preventing tick bites in an area with endemic lyme disease in Baltimore County, Maryland. Am J Epidemiol 2003; 157: 1039-1051.

McKenna D, Faustini Y, Nowakowski J, Wormser GP. Factors influencing the utilization of Lyme disease-prevention behaviors in a high-risk population. J Am Acad Nurse Pract 2004; 16:24-30.

Orloski KA, Hayes EB, Campbell GL, Dennis DT. Surveillance for Lyme disease-United States, 1992-1998. MMWR CDC Surveill Summ 2000; 49:1-11.

Payton JW, Wardlaw DM, Graczyk PA, Bloodworth MR, et al. Social and emotional learning: A framework for promoting mental health and reducing risk behavior in children and youth. J Sch Health 2000; 70:179-185.

Poland GA. Prevention of Lyme disease: A review of the evidence. Mayo Clin Proc 2001; 76:713-724.

Redican KJ, Olsen LK, Mathis RM. A comparison of the cognitive effects of two prototype health education curriculums on selected elementary school children. J Sch Health 1979; 49: 340-342.

Rimer BK, Glanz K, Rasband G. Searching for evidence about health education and health behavior interventions. Health Educ Behav 2001; 28:231-248.

Rosenstock IM. Historical origins of the Health Belief Model. Health Educ Monogr 1974; 2:328-335.

Rosenstock IM, Strecher VJ, Becker MH. Social learning theory and the Health Belief Model. Health Educ Q 1988; 15: 175-183. 
Shadick NA, Daltroy LH, Phillips CB, Liang US, et al. Determinants of tick-avoidance behaviors in an endemic area for Lyme disease. Am J Prev Med 1997; 13:265-270.

Smith G, Wileyto EP, Hopkins RB, Cherry BR, et al. Risk factors for lyme disease in Chester County, Pennsylvania. Public Health Rep 2001; 116 Suppl 1:146-156.

Vazquez M, Muehlenbein C, Cartter M, Hayes EB, et al. Effectiveness of personal protective measures to prevent Lyme disease. Emerg Infect Dis 2008; 14:210-216.

Weimer M. Learner-Centered Teaching: Five Key Changes to Practice. 2nd Edition, San Francisco, California: JosseyBass/Wiley. 2013.

Zibit M, Tooke S, Cui J, Maher N, Shadick N. Beyond Attitude, parental characteristics that predict children's tick checking behavior. Presented at the Annual Scientific Meeting at the American College of Rheumatology, San Francisco, CA, 2008.

Address correspondence to: Nancy A. Shadick Division of Rheumatology, Immunology \& Allergy

Brigham \& Women's Hospital Harvard Medical School Boston, MA 02115

E-mail: nshadick@partners.org 